\section{Application of alternative fixatives to formalin in diagnostic pathology}

\author{
L. Benerini Gatta, ${ }^{1}$ M. Cadei, ${ }^{1}$ P. Balzarini, \\ S. Castriciano, ${ }^{2}$ R. Paroni, ${ }^{2}$ A. Verzeletti, ${ }^{3}$ \\ V. Cortellini, ${ }^{3}$ F. De Ferrari, ${ }^{3}$ P. Grigolato ${ }^{1}$ \\ 'Second Department of Pathology, School \\ of Medicine, University of Brescia; \\ ${ }^{2}$ Copan Italia, Brescia; ${ }^{3}$ Department \\ of Forensic Medicine, School of Medicine, \\ University of Brescia, Italy
}

\section{Abstract}

Fixation is a critical step in the preparation of tissues for histopathology. The aim of this study was to investigate the effects of different fixatives $v s$ formalin on proteins and DNA, and to evaluate alternative fixation for morphological diagnosis and nucleic acid preservation for molecular methods. Forty tissues were fixed for $24 \mathrm{~h}$ with six different fixatives: the gold standard fixative formalin, the historical fixatives Bouin and Hollande, and the alternative fixatives Greenfix, UPM and CyMol. Tissues were stained (Haematoxylin-Eosin, Periodic Acid Schiff, Trichromic, Alcian-blue, High Iron Diamine stainings), and their antigenicity was determined by immunohistochemistry (performed with PAN-CK, CD31, Ki-67, S100, CD68, AML antibodies). DNA extraction, KRAS sequencing, FISH for CEP-17, and flow cytometry analysis of nuclear DNA content were applied. For cell morphology the alternative fixatives (Greenfix, UPM, CyMol) were equivalent to formalin. As expected, Hollande proved to be the best fixative for morphology. The morphology obtained with Bouin was comparable to the one with formalin. Hollande was the best fixative for histochemistry. Bouin proved to be equivalent to formalin. The alternative fixatives were equivalent to formalin, although with greater variability in haematoxylin-eosin staining. It proved the possibility to obtain immunohistochemical staining largely equivalent to that following formalin-fixation with the following fixatives: Greenfix, Hollande, UPM and CyMol. The tissues fixed in Bouin did not provide results comparable to those obtained with formalin. The DNA extracted from samples fixed with alternative fixatives was found to be suitable for molecular analysis.

\section{Introduction}

The fixation method is a crucial step in the histopathological process, as it determines the optimal conservation of the tissue before its analysis. However, this step is also one of the limiting factors in determining deep changes in the tissue. The current fixative of choice is formalin. The use of formalin has a long history in tissue fixation; in 1893, Ferdinand Blum discovered the power of the formaldehyde fixative and began several experiments on the use of formalin in histology and pathology. ${ }^{1}$

This fixative has been used for 150 years and represents an optimal compromise. ${ }^{2}$ It is widely used for preservating the morphology, antigenicity and molecular characteristics of most tissues, and is accepted by most pathologists after standardization of protocols. There are issues, however, that may be improved by an alternative fixation method, such as analysis of fixed tissue comparable with that of frozen tissue, which is better for the conservation of antigens, carbohydrates, lipids, and nucleic acids. Another consideration is that the pathology laboratory uses large amounts of formalin and often underestimates its hazards, because technicians and pathologists are exposed to a dilute solution of formaldehyde. Furthermore, the exposure is daily and in large quantities, so the risk of formaldehyde as a chemical carcinogen must not be underestimated. ${ }^{3-6}$ Over the past 20 years, several laboratories tried to replace formalin with other less toxic fixatives, but the results have been unsatisfactory, owing to alterations in cellular morphology and antigenicity. ${ }^{7}$ The search for an alternative to formalin fixation, which offers better technical performance and greater protection for health workers, is unavoidably needed. ${ }^{8}$

The purpose of this study was to investigate the effects of different fixatives on the characteristics of tissues sent to the laboratory of pathology. The tissues used in this study were sampled and fixed with six different fixatives for 24 h: formalin, Greenfix, UPM, CyMol, Bouin, and Bouin/Hollande (hereinafter Hollande). Greenfix is ethanedial and alcohol based and completely free of formaldehyde, and is the next generation of fixatives. In this work we also took into account other substances currently used in cytology: UPM, which is a combination of ethanol, methanol, isopropyl alcohol and formalin; and CyMol, which is a combination of ethanol, methanol and isopropyl alcohol. Bouin and Hollande, historical fixatives that incorporate picric acid, were used for morphological and histochemical evaluations. Morphology, histochemistry, immunohistochemistry and flow cytometry were assessed.

Another consideration is that some recently discovered factors such as gene amplification and somatic mutations that predict responses to biological therapies in cancer patients require samples suitable for advanced meth-
Correspondence: Dr. Luisa Benerini Gatta, Anatomia e Istologia Patologica II, P.le Spedali Civili 1, 25123 Brescia, Italy.

Tel. +39.030 .3995830 - Fax: +39.030 .3995053 .

E-mail: l.benerini@virgilio.it

Key words: fixation, histochemistry, immunohistochemistry, molecular biology.

Acknowledgments: the authors would like to thank Ms. A. Galletti, Ms. L. Fontana, Ms. T. Gulotta and Mr. F. Alpi for their technical support. Use of the ABI PRISM ${ }^{\circledR} 310$ Genetic Analyzer (Applied Biosystem, Foster City, CA, USA) was provided by the Department of Forensic Medicine, University of Brescia. LBG was supported by a fellowship from the Beretta Foundation, Brescia, Italy.

The work was supported by ex- $60 \%$ funds from the University of Brescia.

Received for publication: 19 May 2011. Accepted for publication: 10 January 2012.

This work is licensed under a Creative Commons Attribution NonCommercial 3.0 License (CC BYNC 3.0).

(C) Copyright L. Benerini Gatta et al., 2012 Licensee PAGEPress, Italy

European Journal of Histochemistry 2012; 56:e12 doi:10.4081/ejh.2012.e12

ods such as gene sequencing and FISH (fluorescence in situ hybridization). Therefore, the fixed tissue samples were analyzed for the applicability of these molecular methods.

\section{Materials and Methods}

\section{Tissue sampling and tissue fixation}

Forty specimens were collected at the $2^{\text {nd }}$ Department of Pathology, Spedali Civili, Brescia, Italy. For this study each biopsy was split into six parts and fixed with Formalin (Bio-optica, Milano, Italy), Bouin, Hollande, Greenfix (Diapath, Bergamo, Italy), UPM or CyMol (Copan Italia, Brescia, Italy). The sources of the biopsies are shown in Table 1. The chemical and bio-hazard characteristics of the fixatives are shown in Table 2. The duration of the fixation process was $24 \mathrm{~h}$. All specimens were then paraffin-embedded.

\section{Histochemistry}

Haematoxylin-eosin (H\&E), Alcian-blue (pH 2.5), Periodic Acid Schiff (PAS), Masson's Trichrome, and High Iron Diamine, were applied using standard staining protocols. 


\section{Immunohistochemistry}

The proteins investigated were: Cytokeratin (CK-PAN Clone MNF116, Dako A/S, Glostrup, Denmark), Ki-67 (Clone MIB-1, Dako A/S), CD31 (Clone 1A10, Leica Biosystems New Castle Ltd., Benton Lene, UK), S100 (Rabbit Polyclonal Antibody, Leica Biosystems New Castle Ltd.), CD68 (Clone KP1, Dako A/S), and Alpha-smooth muscle actin (Clone 1A4, Biocare Medical, LLC, Concord, CA, USA). Immunohistochemical analysis was performed on $4 \mu \mathrm{m}$ sections of fixed, paraffin-embedded tissues. After deparaffinization and hydration, specific antigen retrieval was applied. All samples were processed according to standard protocols. A Novolink Polymer Detecting System kit (Menarini, Firenze, Italy), DAB chromogen substrate, and H\&E counterstains were used. The technical details for each antibody and fixative are shown in Table 3.

\section{Digital image analysis}

Digital images were prepared for analysis using the ImageJR computer program. Image JR is a Java image-processing program developed by the National Institutes of Health (Bethesda, MD, USA, http://rsb.info.nih.gov/ij/ downloaad.html). The colour intensity of each image was automatically measured using a colour deconvolution plugin specific for histochemistry or immunohistochemistry. ${ }^{9}$ Colour contrast was measured using colour histogram analysis.

\section{DNA extraction, PCR and sequencing}

Genomic DNA was obtained from four 10 $\mu \mathrm{m}$ thick sections of paraffin-embedded tissue. All sections were placed in $2 \mathrm{~mL}$ micro centrifuge tubes and dewaxed with successive washes of xylene and absolute, $95 \%$ and $70 \%$ ethanol. After an overnight digestion with $\mathrm{K}$ proteinase at $56^{\circ} \mathrm{C}$, DNA was extracted and purified using a NucleoSpin Tissue Kit (Macherey-Nagel, Düren, Germany) according to the manufacturer's protocol. KRAS PCR was applied to amplify 200 bases of exon 2 with a modified protocol previously described.10 Positive and negative controls were used. The sensitivity curve of the KRAS PCR was determined using $200 \mathrm{ng}, 20 \mathrm{ng}$ and $2 \mathrm{ng}$ of the genomic DNA. The PCR products were sequenced using standard protocols (Applied Biosystem, Foster City, CA, USA). All tests were performed in triplicate to confirm the reproducibility of the results.

\section{FISH analysis}

FISH analysis at interphase was performed using a Chromosome Enumeration Probe (CEP) mapping the centromeric region of chromosome 17 (SpectrumGreen, Vysis,
Downers Grove, IL, USA). Sections $3 \mu \mathrm{m}$ thick were prepared for FISH analysis: the sections were de-paraffinised by three 10-minute washes in xylene, followed by two 5 -minute washes with $100 \%$ ethanol, then processed using pretreatment kit I (Vysis). Briefly, sections were treated with $0.2 \mathrm{~N} \mathrm{HCl}$ for $20 \mathrm{~min}$, washed with buffer 1 and 2 (Vysis) for 3 min, then incubated in pre-treatment solution for $30 \mathrm{~min}$ at $81^{\circ} \mathrm{C}$. After washing with distilled water and buffer 1, the samples were digested with protease solution for $45 \mathrm{~min}$ at $37^{\circ} \mathrm{C}$. Next, the slides were rinsed with buffer 1 and 2 for $5 \mathrm{~min}$ and dried, then fixed with buffered formalin at $4 \%$ final concentration for $1 \mathrm{~min}$ at room temperature, rinsed with buffer 1 and 2 for $5 \mathrm{~min}$, then dehydrated in consecutive $70 \%, 80 \%$ and being dried. Ten $\mu \mathrm{L}$ of centromeric probe for chromosome 17 was applied to each slide and each section was cover-slipped. Denaturation was achieved by incubating the slide at $80^{\circ} \mathrm{C}$ for $10 \mathrm{~min}$ in a Hybridizer; hybridization was undertaken at $37^{\circ} \mathrm{C}$ for $14 \mathrm{~h}$. The cover slips

\begin{tabular}{lc} 
& Number of samples \\
Anatomical site & \\
Lung & 8 \\
Bronchus & 4 \\
\hline Liver & 8 \\
Colon & 2 \\
\hline Ovary & 8 \\
Vulva & 4 \\
\hline Kidney & 2 \\
Skin & 4 \\
\hline Total & 40 \\
\hline
\end{tabular}

were then removed and the slides were immersed in $0.3 \%$ NP40 SSC2X for $1 \mathrm{~min}$ at room temperature, then in $0.3 \mathrm{NP} 40 \mathrm{SSC} 2 \mathrm{X}$ for 2 min at $72^{\circ} \mathrm{C}$. The slides were dried and counterstained with propidium iodide (Vysis). They were examined using a SpectrumGreen filter $100 \%$ ethanol solutions for 1 min each before

Table 1. Tissue collection.

Table 2. Chemical and bio-hazard characteristics of formalin and alternative fixatives.

\begin{tabular}{|c|c|c|c|c|}
\hline Fixatives & $\begin{array}{l}\text { Chemical } \\
\text { composition }\end{array}$ & $\mathrm{pH}$ & $\begin{array}{l}\text { Health } \\
\text { and safety }\end{array}$ & inogenic \\
\hline $\begin{array}{l}\text { Formalin } \\
\text { (neutral buffered) }\end{array}$ & Formaldehyde 4\% & $7-7.2$ & $\begin{array}{l}\mathrm{R} 23 / 24 / 25 ; \mathrm{R} 34 ; R 40 \\
\mathrm{~S} 26 \text { 30/37/39; S45; S21 }\end{array}$ & Yes \\
\hline Bouin's fixative & $\begin{array}{l}\text { Picric acid } \\
\text { Formaldehyde } \\
\text { Glacial acetic acid }\end{array}$ & 1.75 & $\begin{array}{l}\text { R40; R43 } \\
\text { S26; S36/37; S45 }\end{array}$ & Yes \\
\hline Hollande's fixative & $\begin{array}{l}\text { Picric acid } \\
\text { Copper acetate } \\
\text { Formaldehyde } \\
\text { Mercury Cloruro II }\end{array}$ & 3.9 & $\begin{array}{l}\mathrm{R} 23 / 24 / 25 ; \mathrm{R} 43 \\
\mathrm{~S} 28 ; \mathrm{S} 45\end{array}$ & No \\
\hline Greenfix & $\begin{array}{l}\text { Ethandial } \\
\text { Ethanol }\end{array}$ & $4-5.5$ & $\begin{array}{l}\text { R10; R36/38; } \\
\text { S7; S26; S36/37 }\end{array}$ & No \\
\hline UPM & $\begin{array}{l}\text { Ethanol } \\
\text { Methanol } \\
\text { 2-Propanol } \\
\text { Formalin }\end{array}$ & $\begin{array}{c}\text { Not } \\
\text { applicable }\end{array}$ & ND & ND \\
\hline CyMol & $\begin{array}{l}\text { Ethanol } \\
\text { Methanol } \\
\text { 2-Propanol }\end{array}$ & $\begin{array}{c}\text { Not } \\
\text { applicable }\end{array}$ & $\begin{array}{l}\text { R11; R23/24/25; R36; R39; R67 } \\
\text { S16; S33; S23; S24/25 }\end{array}$ & No \\
\hline
\end{tabular}

ND, not determined, research product.

Table 3. Immunohistochemical methods used for the different fixatives.

\begin{tabular}{lllll} 
Primary antibody & Antigen & Dilution & Antigen retrieval (AR) & Fixative* \\
PAN-CK & Epithelial cells & $1: 200$ & Protease XIV 10 min & F, B, H \\
CD31 & Endothelial cells & $1: 50$ & $\begin{array}{l}\text { 3 Cycles Tris/EDTA } \\
\text { 1 Cycle Tris/EDTA }\end{array}$ & F, B, H \\
& & & G, U, C \\
\hline Ki-67 & Ki-67 antigen & $1: 50$ & Citrate buffer & A \\
S100 & S100 protein & $1: 700$ & No AR needed & A \\
CD68 & Macrophages & $1: 50$ & Protease XIV 10 min & A \\
AML & Actin (Smooth Muscle) & $1: 100$ & No AR needed & A \\
\hline
\end{tabular}

*F, formalin; B, Bouin; H, Hollande; G, Greenfix; U, UPM; C, CyMol; A, All fixatives. 
for probe visualisation and a Texas Red filter for visualising the propidium iodide nuclear counterstain. The signals were recorded using a Nikon CCD camera.

\section{Flow cytometry analysis of DNA content}

Flow cytometry was performed on cell nuclei extracted from $50 \mu \mathrm{m}$ sections of paraffinembedded tissue fixed with one of the six different fixatives. Sections were deparaffinized in xylene and rehydrated in a descending ethanol series $(100 \%, 95 \%, 70 \%, 50 \%)$ to deionised water. The hydrated samples were digested in a solution of $0.25 \%$ pepsin (Roche, Basel, Switzerland) for $1 \mathrm{~h}$, then melted in $0.1 \mathrm{~N}$ hydrochloric acid $(\mathrm{pH} 1.5)$ at $37^{\circ} \mathrm{C}$. After centrifugation at $1500 \mathrm{rpm}$ at room temperature, pepsin digestion was stopped with a solution of phosphate buffered saline (PBS) at $\mathrm{pH}$ 8.6 and the nuclear suspension was filtered through a $70 \mu \mathrm{m}$ nylon mesh to remove any undigested tissue or other large debris. DNA was stained overnight with propidium iodide (10 $\mu \mathrm{g} / \mathrm{mL}$ ) (Sigma-Aldrich, St. Louis, M0, USA) resuspended in $0.1 \%$ sodium citrate buffer, and nuclei were analyzed using a Beckman Coulter Epics XL flow cytometer (Beckman Coulter Inc., Brea, CA, USA) equipped with laser excitation. Before analysis the instrument was calibrated with flow-check fluorospheres (Beckman Coulter Inc.) and the DNA channel was set using normal human lymphoid tissue. DNA histograms were obtained from at least 5000 cells per sample cells and were considered not diploid when at least two separate $\mathrm{G} 0$-G1 peaks were present. The DNA index (DI) was calculated from each histogram as the ratio of the G0-G1 peak of the non-diploid population to the G0-G1 peak of normal cells present in the tumour region. The coefficient of variation (CV) of the diploid G0G1 peak was used as a parameter of quality. The analysis software was MultiPlus AV (MultiParameter Data Analysis Software).

\section{Statistical analysis}

Statistical analysis was performed using the Student $t$-test. A value of $\mathrm{P}<0.05$ was considered statistically significant.

\section{Results}

\section{Effects of alternative fixation on cell morphology}

The cell morphology of all samples was analysed. The representative sample shown is liver tissue after fixation using formalin (Figure 1A), Hollande (Figure 1B), Bouin (Figure 1C), Greenfix (Figure 1D), UPM (Figure 1E) and CyMol (Figure 1F) as fixatives followed by paraffin-embedding. Thereafter all samples were

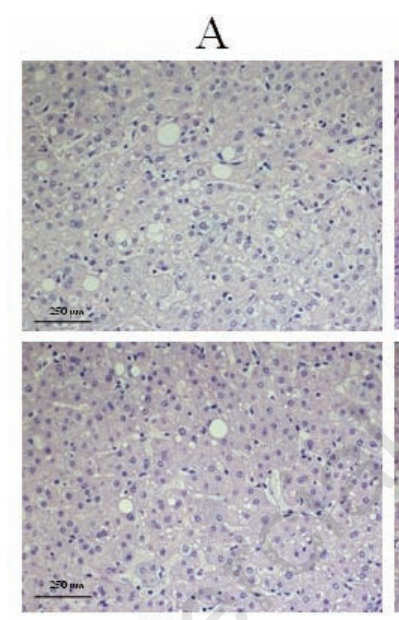

D

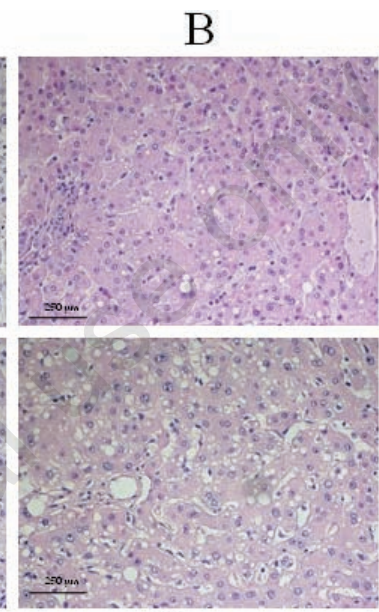

E

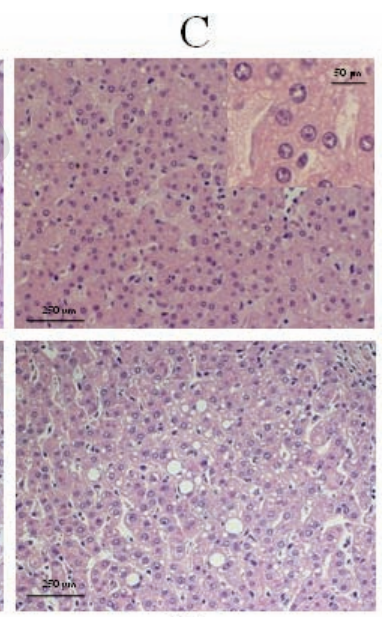

$\mathrm{F}$

Figure 1. Hematoxylin-eosin staining (H\&E). Representative sections of H\&E stained liver biopsy following fixation with: A) formalin; B), Hollande; C), Bouin; D), Greenfix; E), UPM; F), CyMol.

Table 4. Colour intensity analysis of the histochemical staining.

\begin{tabular}{|c|c|c|c|c|c|c|c|}
\hline \multirow[b]{2}{*}{ Staining } & \multirow[b]{2}{*}{ CDP } & \multirow[b]{2}{*}{ Formalin } & \multicolumn{4}{|c|}{ Colour intensiy $($ mean $\pm d s)$} & \multirow[b]{2}{*}{ CyMol } \\
\hline & & & Hollande & Bouin & Greenfix & UMP & \\
\hline \multirow[t]{2}{*}{ H\&E } & 1 & $199.14 \pm 2.01$ & $201.04 \pm 4.22$ & $216.51 \pm 2.06^{*}$ & $200.56 \pm 4.09$ & $206.27 \pm 2.82 *$ & $206.66 \pm 4.27 *$ \\
\hline & 2 & $208.16 \pm 1.61$ & $190.28 \pm 5.34^{*}$ & $184.01 \pm 4^{*}$ & $207.22 \pm 4.34^{*}$ & $196.44 \pm 5.22 *$ & $182.36 \pm 9.34 *$ \\
\hline \multirow[t]{2}{*}{ PAS } & 1 & $211.82 \pm 9.42$ & $165.93 \pm 7.26^{*}$ & $176.54 \pm 6.99 *$ & $182.14 \pm 8.83^{*}$ & $185.47 \pm 5.06^{*}$ & $192.03 \pm 8.3^{*}$ \\
\hline & 2 & $32.23 \pm 4.51$ & $14.46 \pm 1.99 *$ & $4.83 \pm 0.41^{*}$ & $15.89 \pm 4.58^{*}$ & $31.47 \pm 0.32$ & $8.02 \pm 0.46 *$ \\
\hline \multirow[t]{2}{*}{ Alcian-blue } & 1 & $129.55 \pm 9.69$ & $170.05 \pm 12.89 *$ & $183.17 \pm 7.45^{*}$ & $158.37 \pm 11.89 *$ & $150.17 \pm 4.49 *$ & $159.53 \pm 3.42 *$ \\
\hline & 2 & $135.42 \pm 5.65$ & $166.25 \pm 7.54^{*}$ & $180.74 \pm 10.02 *$ & $192.33 \pm 4.58^{*}$ & $189.92 \pm 2.2^{*}$ & $186.79 \pm 7.97 *$ \\
\hline \multirow[t]{2}{*}{ Trichrome } & 1 & $145.96 \pm 12.94$ & $167.7 \pm 1.39 *$ & $178.31 \pm 17.48^{*}$ & $145.03 \pm 15.13$ & $134.76 \pm 20.21$ & $123.95 \pm 12.73^{*}$ \\
\hline & 2 & $202.57 \pm 11.32$ & $176.03 \pm 12.05^{*}$ & $228.41 \pm 4.92 *$ & $179.54 \pm 9.09 *$ & $204.6 \pm 13.35$ & $163.29 \pm 8.16^{*}$ \\
\hline \multirow[t]{4}{*}{ HID } & $1 \mathrm{~A}$ & $189.04 \pm 1.32$ & $166.40 \pm 47.73$ & $182.17 \pm 0.99 *$ & $159.29 \pm 45.41$ & $163.83 \pm 53.31$ & $175.33 \pm 23.33$ \\
\hline & $1 \mathrm{~B}$ & $168.19 \pm 49.12$ & $102.42 \pm 2.38$ & $104.33 \pm 1.32$ & $113.92 \pm 1.5$ & $104.18 \pm 7.74$ & $151.83 \pm 2.23$ \\
\hline & $2 \mathrm{~A}$ & $111.02 \pm 14.6$ & $135 \pm 3^{*}$ & $127.72 \pm 1.61$ & $137.96 \pm 5.18 *$ & $111.9 \pm 6.15$ & $140.3 \pm 18.74^{*}$ \\
\hline & $2 \mathrm{~B}$ & $176.5 \pm 2.82$ & $193.31 \pm 3.8^{*}$ & $183.41 \pm 3.88^{*}$ & $190.55 \pm 1.02 *$ & $194.10 \pm 2.94 *$ & $193.54 \pm 2.5^{*}$ \\
\hline
\end{tabular}

All staining slides were examined under the light microscope (Olympus, Vanox, AHBT3). One representative field from each section was selected and digitally acquired, using 20X magnification objective lens. All images were captured using the same light filter settings. The colour deconvolution plugin (CDP) was applied to each image and the colour intensity histogram was determined. Ten areas of each image were analysed (with mean colour intensity recovery) in order to determine the average intensity of the CDP colour 1 and 2 . Colour scale: values $0-255$, with 0 , maximum value; 255 , minimum value. ${ }^{*} \mathrm{P}<0.05$; HID, High Iron Diamine. Colour $1 \mathrm{~A}$, stroma; colour $1 \mathrm{~B}$, cartilage; colour $2 \mathrm{~A}$, secret 1 ; colour $2 \mathrm{~B}$, secret 2. 
stained with haematoxylin-eosin. Light microscopy revealed that Greenfix, UPM and CyMol preserved cell integrity, giving morphological information similar to that obtained with formalin: no differences were identified in cell architecture, cytoplasmic and nuclear morphology, or tinctorial reactions. The morphology of samples fixed with UPM and CyMol in particular offered a good definition of hepatocytes and portal tracts. Hollande showed the same results as Greenfix with the exception of an excessive tinctorial reaction. A similar morphology was seen in sections from tissues fixed with Bouin fixative, with a higher resolution of chromatin in the nucleolus, and the nuclear matrix background being more lightly stained. The mean and standard deviation of all haematoxylin-eosin (H\&E) staining intensities, as assessed by Colour Deconvolution and colour intensity analysis of the colour histogram, are given in Table 4 . Haematoxylin intensity was significantly lower with Bouin, UPM, and Cymol fixation. Eosin intensity was greater with all alternative fixatives. The H\&E staining contrast was also measured and the values are given in Table 5 . The samples fixed in Hollande or Bouin offered the best colour contrast, although formalin is currently regarded as the gold standard.

\section{Histochemical and immunohisto- chemical analysis from alternative fixatives}

For histochemical staining the following qualitative parameters were assessed doubleblind: epithelial-stromal contrast, the prevalence of positivity, and the intensity of colour The stains used were PAS, Masson's Trichrome and Alcian-blue, and High Iron Diamine (Figure 2). Microscopic examination of the bronchial wall stained with PAS (Figure $2 \mathrm{~A} / \mathrm{I}$ ) and fixed with formalin revealed good staining and clear cartilage identification. Greenfix, UPM, CyMol and Hollande allowedto show the secretion, while in tissue fixed with Bouin the staining was very intense. With Alcian-blue staining (Figure $2 \mathrm{~A} / \mathrm{II}$ ), Hollande was the best fixative; tissue fixed with Bouin, UPM and Cymol showed Alcian-blue staining spreading into the cartilage matrix. For UPM and Cymolfixed tissue, staining was very selective for chondrocytes. The samples fixed with Greenfix showed less intense staining but retained colour fidelity. With Masson's Trichrome staining (Figure $2 \mathrm{~A} / \mathrm{III}$ ), formalin gave good results in terms of colour, contrast, and positivity; the Greenfix and Hollande fixatives were superior as the tissues fixed in these showed greater definition, while samples fixed with Bouin offered less definition. CyMol fixation proved to be superior to formalin in terms of colour brightness and definition, while UPM gave results equivalent to formalin. Good results were obtained with formalin and High Iron Diamine staining. Greenfix fixation gave results equivalent to formalin, while UPM and CyMol were better, as were the fixatives Hollande and Bouin (Figure $2 \mathrm{~A} / \mathrm{IV}$ ).

All histochemical staining was also analysed using the Image ${ }^{\mathrm{R}}$ program and the quantita-

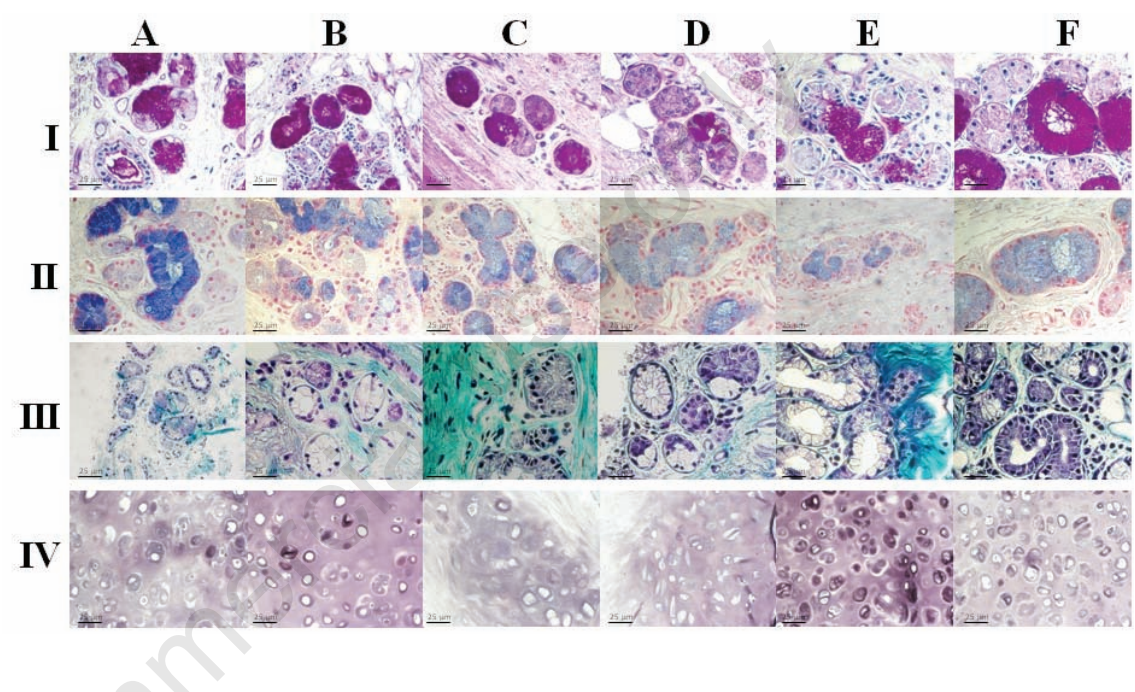

Figure 2. Histochemistry. Bronchial tissue stained with: I), PAS; II) Alcian-blue; III) Trichrome; IV) High Iron Diamine (IV), following fixation with: A) formalin; B) Hollande; C) Bouin; D), Greenfix; E), UPM; F), CyMol.

Table 5. Colour contrast analysis of the histochemical staining.

\begin{tabular}{|c|c|c|c|c|c|c|c|}
\hline \multirow[b]{2}{*}{ Staining } & \multirow[b]{2}{*}{ M } & \multirow[b]{2}{*}{ Formalin } & \multirow[b]{2}{*}{ Hollande } & \multicolumn{2}{|c|}{ Colour contrast (mean $\pm \mathrm{ds}$} & \multirow[b]{2}{*}{ UMP } & \multirow[b]{2}{*}{ CyMol } \\
\hline & & & & Bouin & Greenfix & & \\
\hline \multirow[t]{3}{*}{$\mathrm{H} \& \mathrm{E}$} & $\mathrm{r}$ & $174.36 \pm 8.67$ & $187.12 \pm 3.33^{*}$ & $200.77 \pm 3.71^{*}$ & $177.77 \pm 2.18$ & $198.2 \pm 6.34^{*}$ & $184.5 \pm 9.95$ \\
\hline & g & $163.997 \pm 9.21$ & $159.67 \pm 3.68 *$ & $163.88 \pm 3.43$ & $171.66 \pm 2.63$ & $175.94 \pm 4.74$ & $160.44 \pm 10.7$ \\
\hline & b & $177.07 \pm 10.39$ & $189.03 \pm 3.06$ & $195.88 \pm 4.15^{*}$ & $180.44 \pm 3.97$ & $190.71 \pm 8.97$ & $180.36 \pm 12.56$ \\
\hline \multirow[t]{3}{*}{ PAS } & r & $224.95 \pm 8.88$ & $186.88 \pm 13.94^{*}$ & $201.88 \pm 8.28^{*}$ & $211.48 \pm 5.61$ & $193.87 \pm 6.78^{*}$ & $187.94 \pm 4.45^{*}$ \\
\hline & g & $204.76 \pm 17.22$ & $150.44 \pm 24.35^{*}$ & $152.25 \pm 11.97^{*}$ & $196.51 \pm 16.76^{*}$ & $167.3 \pm 14.09 *$ & $120.55 \pm 16.17^{*}$ \\
\hline & b & $229.73 \pm 8.66$ & $204.41 \pm 10.32 *$ & $219.37 \pm 6.74$ & $233.91 \pm 3.53$ & $208.62 \pm 5.22 *$ & $200.77 \pm 6.81^{*}$ \\
\hline \multirow[t]{3}{*}{ Alcian } & r & $195.97 \pm 12.73$ & $209.71 \pm 6.36$ & $201.9 \pm 5.22$ & $194.77 \pm 2.46$ & $199.95 \pm 4.61$ & $198.13 \pm 1.92$ \\
\hline & g & $196.63 \pm 10.98$ & $198.69 \pm 6.1$ & $191.3 \pm 4.92$ & $184.25 \pm 2.38$ & $195.06 \pm 5.51$ & $197.04 \pm 1.63$ \\
\hline & b & $217.41 \pm 5.43$ & $204.77 \pm 6.72$ & $200.42 \pm 3.37$ & $187.6 \pm 2.6^{*}$ & $199.03 \pm 3.94^{*}$ & $201.41 \pm 1.52^{*}$ \\
\hline \multirow[t]{3}{*}{ Trichrome } & r & $200.72 \pm 13.65$ & $203.88 \pm 8.81$ & $161.59 \pm 4.45^{*}$ & $192.5 \pm 7.6$ & $120.03 \pm 25.19 *$ & $147.4 \pm 11.65^{*}$ \\
\hline & b & $208.11 \pm 11.22$ & $205.99 \pm 12.56$ & $215.36 \pm 1.1$ & $193.07 \pm 9.07$ & $167.18 \pm 21.79 *$ & $152.98 \pm 10.61^{*}$ \\
\hline & b & $215.57 \pm 6.55$ & $219.44 \pm 8.63$ & $210.39 \pm 0.95$ & $212.27 \pm 3.96$ & $189.57 \pm 13.67^{*}$ & $167.78 \pm 9.97^{*}$ \\
\hline \multirow[t]{3}{*}{ HID } & $\mathrm{r}$ & $157.68 \pm 3.85$ & $160.14 \pm 6.28$ & $155.26 \pm 3.12$ & $157.33 \pm 1.88$ & $150.13 \pm 2.43^{*}$ & $160.01 \pm 1.54$ \\
\hline & g & $160.54 \pm 2.28$ & $166.92 \pm 4.8$ & $155.2 \pm 1.97 *$ & $156.72 \pm 3.34$ & $157.43 \pm 1.22$ & $164.23 \pm 1.64 *$ \\
\hline & b & $161.46 \pm 2.71$ & $167.07 \pm 2.94 *$ & $156.02 \pm 2.16^{*}$ & $155.2 \pm 2.63^{*}$ & $157.63 \pm 0.97$ & $163.22 \pm 1.62$ \\
\hline
\end{tabular}

The colour contrast of each slide was measured automatically using the colour histogram analysis of the ImageJR computer program. HID, high iron diamine; M, colour histogram mean; r, red; g, green; b, blue. Colour scale: values $0-255$, with 0 , maximum value; 255 , minimum value. ${ }^{*} \mathrm{P}<0.05$. 
tive results of colour intensity and contrast are given in Tables 4 and 5. All samples fixed with the alternative fixatives had higher colour intensities than formalin. The Alcian-blue staining of the samples fixed with alternative fixatives had a lower colour intensity. The biopsies fixed with Hollande and Bouin had a higher colour intensity, those fixed in Greenfix and UPM showed an equivalent staining intensity and those fixed with CyMol showed only minor differences. High Iron Diamine staining of the stroma and cartilage of all samples was equivalent to formalin, while the secrete colour intensity was greater with all alternative fixatives. Very high colour contrast was obtained with PAS staining of samples fixed in Hollande, Bouin, UPM, or CyMol; with Masson's Trichrome staining of UPM and CyMol-fixed tissue; and with High Iron Diamine staining of Bouin-fixed sections. The colour contrast was equivalent to formalin for all other samples.

The immunoreactions of the antibodies PAN-CK, CD31, Ki-67, S100, CD68, and AML were evaluated. The specificity of the reactions was evaluated in a double-blind screening. The colour intensity of the DAB-specific signal and the background noise was measured using the Image $J^{\mathrm{R}}$ program. The results for all the immunoreactions are given in Table 6. As shown in Figure 3 for the ovarian cancer tissue in PAN-CK (panel I), immunoreactions with tissue fixed in formalin gave excellent positive diffuse and dense staining. Use of Greenfix gave excellent positive diffuse staining, while good focal positivity was obtained with Hollande fixation. With Bouin a positive medium-weak focal staining was seen; with UPM fixation the staining was excellently intense and widespread, with good selective membrane staining; while with CyMol fixation, PAN-CK gave a good positive
I

A

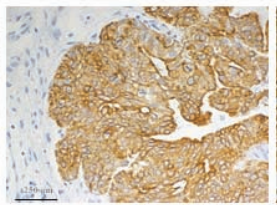

C

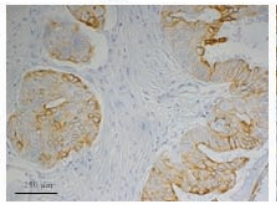

$\mathbf{E}$

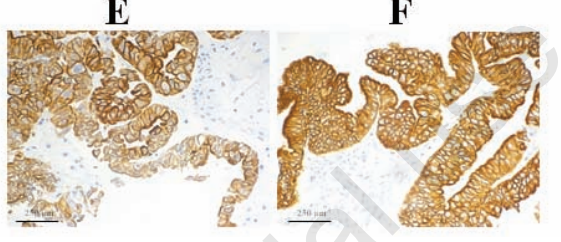

II

A

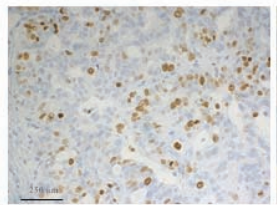

C

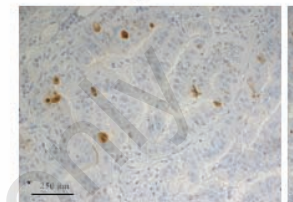

$\mathbf{E}$

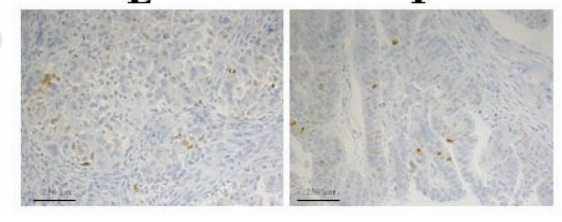

Figure 3. Immunohistochemistry. Immunohistochemical staining with of mixed endometrioid serous papillary carcinoma of ovary using: I), CK-PAN and II), Ki-67 antibodies following fixation with: A) formalin; B) Hollande; C) Bouin; D), Greenfix; E), UPM; F), CyMol.

Table 6. Colour intensity analysis of the immunohistochemical staining.

\begin{tabular}{|c|c|c|c|c|c|c|c|}
\hline \multirow[t]{2}{*}{ Immunostaining } & \multicolumn{7}{|c|}{ Colour intensity (mean $\pm \mathrm{ds}$ ) } \\
\hline & CDP & Formalin & Hollande & Bouin & Greenfix & UMP & CyMol \\
\hline CK-PAN & & $\begin{array}{l}247.66 \pm 3 \\
120.68 \pm 9 \\
239.14 \pm 2.58\end{array}$ & $\begin{array}{l}241.95 \pm 5.27 \\
102.58 \pm 10.42 * \\
232.22 \pm 6.44\end{array}$ & $\begin{array}{l}220.01 \pm 14.31^{*} \\
158.73 \pm 4.3^{*} \\
217.25 \pm 6.18^{*}\end{array}$ & $\begin{array}{c}244.65 \pm 0.62 \\
64.74 \pm 6.21^{*} \\
231.77 \pm 6.29\end{array}$ & $\begin{array}{c}242.58 \pm 3.3 \\
95.65 \pm 7.09^{*} \\
250.42 \pm 1.65^{*}\end{array}$ & $\begin{array}{c}257.67 \pm 14.22 \\
95.65 \pm 13.47^{*} \\
251.41 \pm 2.88^{*}\end{array}$ \\
\hline Ki-67 & $\begin{array}{l}1 \\
2 A \\
2 B\end{array}$ & $\begin{array}{r}220.37 \pm 2.17 \\
79.14 \pm 12.33 \\
230 \pm 10.24\end{array}$ & $\begin{array}{c}211.57 \pm 2.75^{*} \\
54.11 \pm 2.8^{*} \\
225.34 \pm 5.83\end{array}$ & $\begin{array}{c}208.94 \pm 20.03^{*} \\
51.24 \pm 23.99 \\
225.18 \pm 2\end{array}$ & $\begin{array}{c}204.78 \pm 7.17^{*} \\
59.15 \pm 10.55^{*} \\
212.3 \pm 5.17^{*}\end{array}$ & $\begin{array}{l}217.68 \pm 1.78 \\
124.68 \pm 26.51^{*} \\
208.91 \pm 5.05^{*}\end{array}$ & $\begin{array}{c}214.38 \pm 2.55^{*} \\
88.69 \pm 3.33 \\
213.24 \pm 5.29^{*}\end{array}$ \\
\hline CD31 & $\begin{array}{l}1 \\
2 \mathrm{~A} \\
2 \mathrm{~B}\end{array}$ & $\begin{array}{r}177.41 \pm 3.43 \\
57.84 \pm 8.93 \\
183.78 \pm 3.29\end{array}$ & $\begin{array}{c}182.61 \pm 3.92 \\
89.88 \pm 3.12^{*} \\
179.46 \pm 2.33\end{array}$ & $\begin{array}{r}165.86 \pm 4.07^{*} \\
36.44 \pm 8.02^{*} \\
171.51 \pm 6.49 *\end{array}$ & $\begin{array}{c}176.17 \pm 2.01 \\
32.31 \pm 3.68 * \\
177.32 \pm 7.37\end{array}$ & $\begin{array}{c}179.43 \pm 3.82 \\
27.54 \pm 6.24^{*} \\
181.25 \pm 1.52\end{array}$ & $\begin{array}{r}163.47 \pm 9.37^{*} \\
31.76 \pm 8.06^{*} \\
158 \pm 9.81^{*}\end{array}$ \\
\hline CD68 & $\begin{array}{l}1 \\
2 \mathrm{~A} \\
2 \mathrm{~B}\end{array}$ & $\begin{array}{c}224.82 \pm 1.89 \\
52.88 \pm 14.21 \\
211.85 \pm 7.3\end{array}$ & $\begin{array}{r}206.75 \pm 4.71^{*} \\
26.9 \pm 7.65^{*} \\
190.82 \pm 9.29^{*}\end{array}$ & $\begin{array}{c}194.09 \pm 3.84^{*} \\
20.86 \pm 4.64^{*} \\
162.24 \pm 15.39^{*}\end{array}$ & $\begin{array}{r}226.46 \pm 3.96 \\
12.29 \pm 2.23^{*} \\
138.38 \pm 3.82^{*}\end{array}$ & $\begin{array}{c}223.23 \pm 3.25 \\
23.31 \pm 4.83^{*} \\
146.39 \pm 8.61^{*}\end{array}$ & $\begin{array}{r}239.79 \pm 2.43^{*} \\
23.34 \pm 8.63^{*} \\
139.55 \pm 9.68^{*}\end{array}$ \\
\hline AML & $\begin{array}{l}1 \\
2 \mathrm{~A} \\
2 \mathrm{~B}\end{array}$ & $\begin{array}{l}167.27 \pm 7.38 \\
37.897 \pm 9.048 \\
195.39 \pm 1.95\end{array}$ & $\begin{array}{r}166.19 \pm 1.07 \\
41.37 \pm 1.17 \\
177.46 \pm 0.8^{*}\end{array}$ & $\begin{array}{c}172.2 \pm 1.76 \\
42.17 \pm 1.22 \\
179.52 \pm 1.12 *\end{array}$ & $\begin{array}{c}170.01 \pm 2.14 \\
16.67 \pm 1.01 * \\
177.52 \pm 0.68 *\end{array}$ & $\begin{array}{r}177.41 \pm 3.29 * \\
13.46 \pm 3.94 * \\
177.39 \pm 1.36 *\end{array}$ & $\begin{array}{r}184.85 \pm 4.25^{*} \\
19.28 \pm 4.37^{*} \\
187.72 \pm 1.85^{*}\end{array}$ \\
\hline S100 & $\begin{array}{l}1 \\
2 \mathrm{~A} \\
2 \mathrm{~B}\end{array}$ & $\begin{array}{c}202.09 \pm 3.49 \\
18.35 \pm 3.32 \\
214.22 \pm 10.98\end{array}$ & $\begin{array}{c}156.26 \pm 51 \\
21.64 \pm 0.58 \\
222.29 \pm 0.96\end{array}$ & $\begin{array}{c}219.66 \pm 1.97^{*} \\
21.77 \pm 0.93 \\
220.46 \pm 1.18\end{array}$ & $\begin{array}{c}206.69 \pm 0.87^{*} \\
48.88 \pm 5.66^{*} \\
215.76 \pm 4.26\end{array}$ & $\begin{array}{c}200.65 \pm 0.32 \\
21.56 \pm 2.16 \\
183.32 \pm 9.94 *\end{array}$ & $\begin{array}{c}214 \pm 9.85 \\
24.26 \pm 1.11 * \\
222.39 \pm 1.77\end{array}$ \\
\hline
\end{tabular}

Digital images were prepared for analysis using the Image $J^{R}$ computer program. Colour intensity of each image was measured automatically using a colour deconvolution plugin (CDP) specific for immunohistochemistry. 1, haematoxylin; $2 \mathrm{~A}$, specific signal; $2 \mathrm{~B}$, background. Colour scale: values $0-255$, with 0 , maximum value; 255 , minimum value. ${ }^{*} \mathrm{P}<0.05$. 
spread, but was less selective than in tissues fixed with UPM. After fixation with formalin or Greenfix, Ki-67 staining showed good, intense positivity (panel II), Bouin Hollande fixation resulted in a weaker positive staining than formalin, while the tissues fixed with UPM or CyMol gave very weak positivity. For CD31 the colour intensity was minor with Bouin or CyMol fixation. The CD68-specific signal was better with all alternative fixatives than with formalin, although all fixatives resulted in a higher background staining than found with formalin fixation. Equivalent intensity of colour signal was obtained in tissues fixed with Hollande, Bouin, or UPM. Significantly higher colour signal was obtained in tissues fixed with Greenfix or CyMol. The background noise was equivalent for all fixatives except UPM, with which produced lower background staining.

\section{Alternative fixation and quality of molecular biology methods}

Molecular analysis in pathology is of increasing importance in diagnostics and for this reason it is essential that tissues are fixed and processed properly with fixatives that do not damage the nuclear material and thus pre-
A

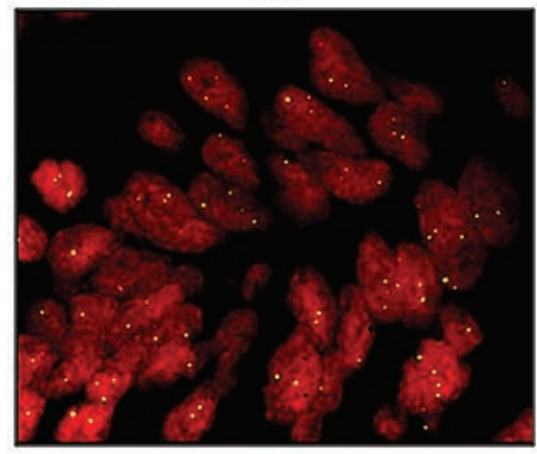

C

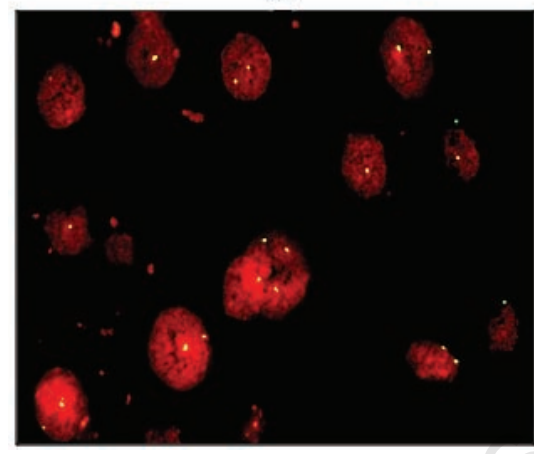

B

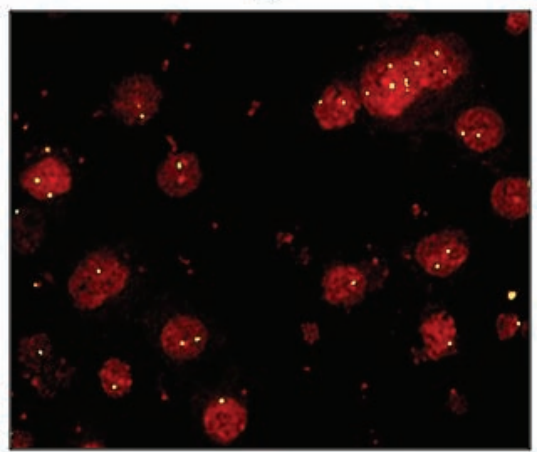

D

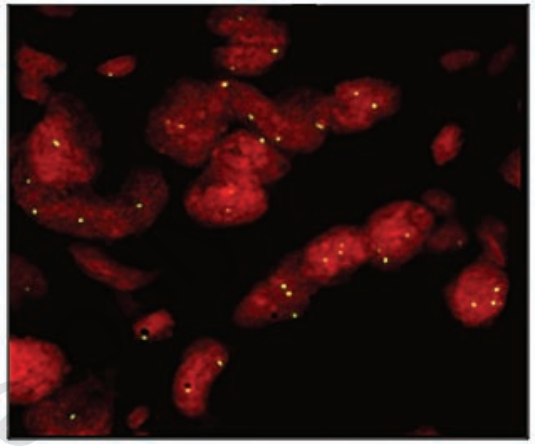

Figure 5. FISH analysis. The signal intensity of the centromeric probe is similar in: A), formalin and B), Greenfix; C), UPM and D) CyMol fixed liver tissue.

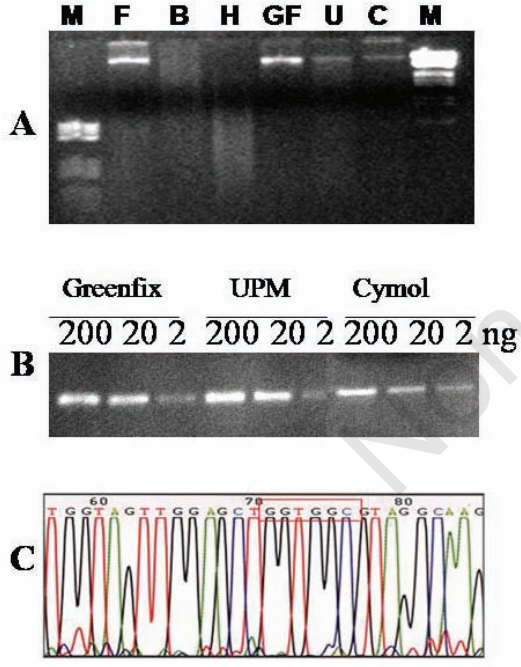

Figure 4. Molecular biology. A), electrophoresis of DNA extracted from liver tissue fixed with formalin $(\mathrm{F})$, Bouin $(\mathrm{B})$, Hollande (H), Greenfix (GF), UPM (U) and $\mathrm{CyMol}(\mathrm{C})$. The bands are similar in $\mathrm{F}$, GF, U and C. B), PCR obtained with 200, 20 and 2 ng of DNA extracted from tissues fixed in Greenfix, UPM, CyMol. The amplification was achieved even at low concentrations of DNA with the three alternative fixatives. C), sequence analysis of the DNA amplified and purified from samples fixed with CyMol demonstrated a K-RAS wild type.
A
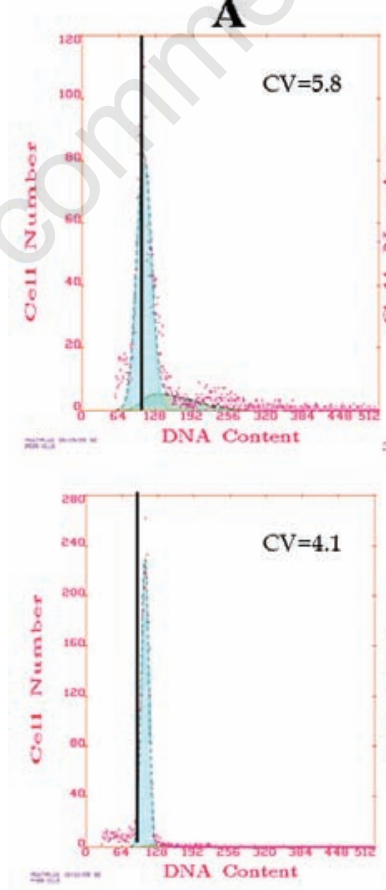

D
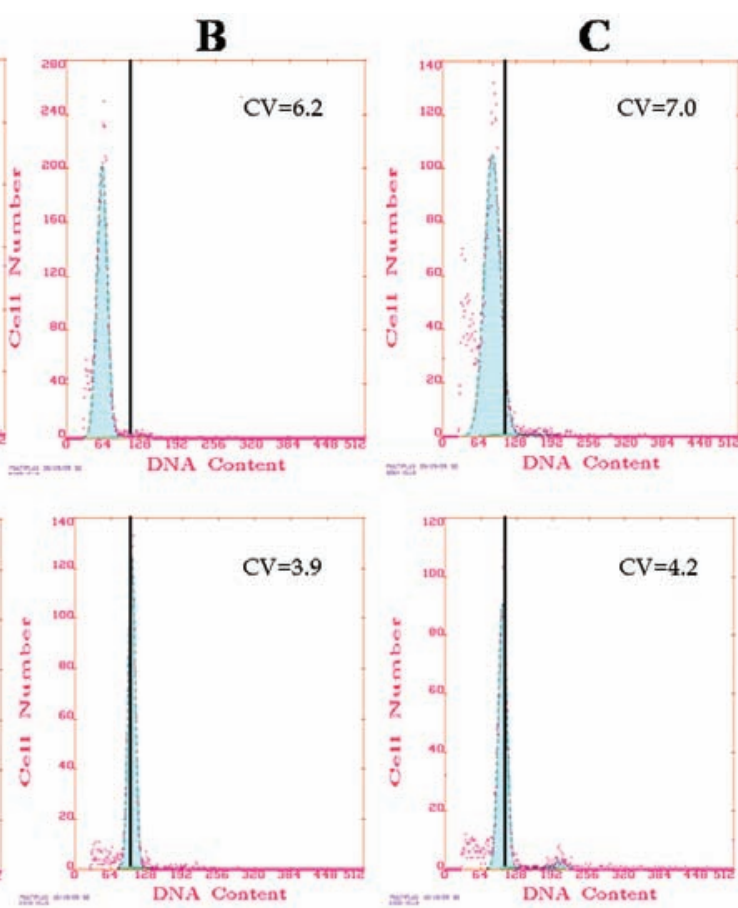

$\mathbf{E}$

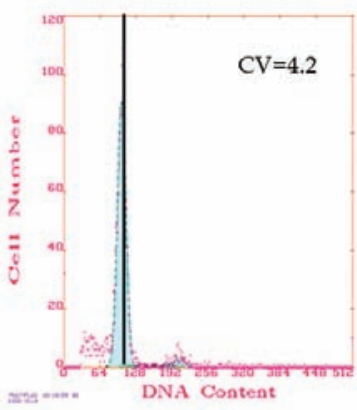

$\mathbf{F}$

Figure 6. Flow cytometry analysis of DNA. Flow cytometry analysis of DNA content of lung tissue showed that the fixatives Greenfix, UPM, CyMol (D-E-F) gave results similar to formalin fixation (A). Shift left of the control is more evident in the two samples fixed with Bouin (C) and Hollande (B). 
vent molecular genetic analysis. We analyzed the following parameters: quality and quantity of DNA extracted from fixed tissues, and the specificity and sensitivity of PCR diagnostic applicability of these samples. DNA extracted from samples fixed in Greenfix gave better results than those fixed in formalin: a higher percentage of high molecular weight DNA was obtained (as determined by the presence of a discrete band with high molecular weight). The UPM and CyMol fixatives offered comparable results to formalin. With Bouin or Hollande fixation, the DNA migrated on an agarose gel as a smear (Figure 4A). PCR was performed for the KRAS gene and the specificity was evaluated by electrophoresis, and the sensitivity with serial dilutions of DNA. With regard to specificity, Greenfix, UPM and CyMol were comparable with formalin, while Hollande and Bouin produced unsatisfactory results. To assess the sensitivity of alternative fixatives, PCR was performed on serially diluted DNA (200 ng - 20 ng - 2 ng) (Figure 4B). DNA extracted from samples fixed with alternative fixatives was found to be suitable for molecular sequence analysis. Indeed, the electropherograms showed high, defined peaks and little background noise (no nonspecific peaks) (Figure 4C). For FISH analysis, a good fixative should preserve the nuclear morphology while concomitantly permeabilizing all cells for the labeled probe. We evaluated the biopsies of liver and ovary tissues after hybridization with CEP17 probe. The results obtained in this study indicate that Greenfix, UPM and Cymol, provided the best maintenance of morphology, nuclear and probe signals. Bouin's fixative and Hollande's fixative gave very poor results indicating deterioration in quality of interphase FISH signals (Figure 5). Flow cytometry was performed on nuclei obtained from samples fixed in formalin, Bouin, Hollande, Greenfix, UPM and CyMol. The DNA index (DI) was always equal to 1 (normal tissue). The sub-G0G1 area represents debris negligible for analysis. The DNA content obtained after fixation with Greenfix, UPM and CyMol gave similar results to formalin fixation; in particular, fixation with alcoholic mixtures produced a fluorescent profile comparable with the control tissue (Figure 6 A,B,D,E,F). These data, and a reduction of the coefficient of variation (data not shown), document good quality extracted DNA. In contrast, the DNA samples from samples fixed with Bouin or Hollande showed a reduction of fluorescence intensity (different dye absorption at the cellular level), with a leftward shift compared to the formalin fixed samples (Figure 6 B,C).

\section{Discussion}

To date, $4 \%$ formaldehyde solution (10\% formalin) for fixation has been universal, preserving a wide range of tissues and tissue components. Nevertheless, in more than 100 years of use, certain chemical and functional inadequacies have only been partly overcome. ${ }^{11}$ The peculiarities of formalin include the slow formation of covalent bonds in aqueous solution with rapid spread into the tissues. In a dilute solution (4\%) formalin is not present in the free state but as methyleneglycol, which can react with the -NH2 groups of proteins, forming methylene protein bridges (cross-linking). ${ }^{12}$ Furthermore, formaldehyde modifies the conformation of macromolecules, altering the tertiary and quaternary structures of proteins, although the primary and secondary structures do not undergo substantial changes. The conformational changes of proteins can induce non-antigen recognition of antibodies that are used in immunohistochemistry. ${ }^{13}$ This problem has been tackled through the development and standardization of Epitope Retrieval methods (treatment with protease, heat, etc.). These methods allow the antigenicity of many markers to be recovered. ${ }^{14}$ However, this is not a physiological condition, and is subject to change due to variables inherent in methods (changes in temperature, $\mathrm{pH}$, molarity of solutions, etc.). The chemical and physical parameters (time, temperature, $\mathrm{pH}$, volume ratio in surgical specimen/fixative) may also influence the result. The fixation time, for example, will greatly influence the histopathological findings: a too short time my cause signal reduction in the centre of the section rather than along the edges, while prolonged fixation can generate the opposite effect. In addition, fixation with formaldehyde can generate free aldehyde groups in tissues, causing a non-specific antigenic response (production of false positives). ${ }^{15}$ Recently, the need for genetic typing of tumours in order to determine the predictors of response to targeted biological therapies has required the use of molecular biological techniques on tissues that have been fixed and embedded in paraffin blocks. However, it is known that formaldehyde interacts chemically with DNA in a similar manner to the way it does with proteins. ${ }^{16}$ Formaldehyde reacts with DNA to form hydroxymethylene bridges between two amino groups. Treatment with formalin may cause apurinic and apirimidinic sites, DNA degradation, and cross-linking of cytosine, with the consequent production of aberrant mutations. ${ }^{17}$

So far, since histopathological diagnosis involves the use not only of traditional methods like histochemical stains, but also of spe- cial investigations such as immunohistochemistry and molecular methods (sequencing and FISH), we have compared the results obtained after formalin fixation $v s$ alternative fixatives. We considered alternative fixatives that are alcohol-based mixtures of fixatives. Ethanol, the main coagulant fixative used in histopathology since antiquity, removes water molecules, thus destabilizing, altering the tertiary structure and denaturing proteins. This process does not affect the majority of antigens, but most of the CD (cluster of differentiation) molecules, and some antigens that are particularly rich in carbohydrates, may be deprived of their antigenicity. The effect of ethanol on DNA is minimal. Indeed, ethanol causes reversible denaturation of DNA. After rehydration, DNA can be used for molecular biology techniques. ${ }^{18}$

The mixtures we have investigated as fixatives are Greenfix, a commercial fixative for histology based on ethanedial and alcohol, and two solutions that are used for the transport of biological material, UPM (ethanol, methanol, isopropyl alcohol and formalin) and CyMol (ethanol, methanol and isopropyl alcohol). We have also used the historical fixatives Bouin and Holland, which incorporate picric acid, as controls for the morphological and histochemical evaluations. Despite the assumed ideal that a liquid fixative should preserve the tissue in conditions as close as possible to those in fresh tissue, every fixation method in reality causes artefacts, including formalin, which induces major changes in the biochemical characteristics of the tissues. Naturally, a pathologist is accustomed to this by years of work experience and literature that details the histological features induced by artefacts caused by formalin. From the morphological point of view all the fixatives used in our study can be considered as valid substitutes for formalin.

Ultimately, the morphological diversity due to alternative fixation should not preclude the formulation of a diagnosis. With regard to histochemical and immunohistochemical analysis, Greenfix has proved a workable substitute for formalin. UPM and CyMol have produced acceptable results, but less satisfactory than Greenfix. Bouin and Hollande have worked well for histochemistry, but are not suitable for molecular applications. ${ }^{19}$ In molecular biology analysis, Greenfix proved to be significantly superior to formalin; UPM and CyMol gave satisfactory results, while Bouin and Hollande are not recommended for this type of investigation because of the precipitation of DNA. In FISH analysis, Greenfix has emerged as a possible substitute for formalin. UPM and CyMol gave poorer results than Greenfix, but were still acceptable, while Bouin and Hollande were not suitable for this type of investigation. The flow cytometry of ploidy revealed that Greenfix, 
UPM and CyMol are comparable to formalin. Greenfix proved to be a valid substitute for formalin as it gave satisfactory results for all of the investigations conducted. Bouin and Hollande, having demonstrated limitations in molecular biology, FISH and flow cytometry, are not suitable as substitutes for formalin. UPM and CyMol may be regarded as potential substitutes for formaldehyde with the possibility of technical improvement and standardization of protocols.

\section{References}

1. Puchtler H, Meloan SN. On the chemistry of formaldehyde fixation and its effects on immunohistochemical reactions. Histochemistry 1985;82:201-4.

2. Plénat F, Antunes L, Haller T, PietOunnoughene M, Klein-Monhoven N, Champigneulle J, et al. Formaldehyde fixation in the third millennium. [Article in French]. Ann Pathol 2001;21:29-47.

3. Binetti R, Costamagna FM, Marcello I. Development of carcinogenicity classifications and evaluations: the case of formaldehyde. Ann Ist Super Sanita 2006;42:132-43.

4. Lassalle S, Hofman V, Marius I, GavricTanga V, Brest P, Havet K, et al. Assessment of morphology, antigenicity, and nucleic acid integrity for diagnostic thy- roid pathology using formalin substitute fixatives. Thyroid 2009;19:1239-48.

5. Stanta G, Mucelli SP, Petrera F, Bonin S, Bussolati G. A novel fixative improves opportunities of nucleic acids and proteomic analysis in human archive's tissues. Diagn Mol Pathol 2006;15:115-23.

6. Costa S, Coelho P, Costa C, Silva S, Mayan 0 , Santos LS, et al. Genotoxic damage in pathology anatomy laboratory workers exposed to formaldehyde. Toxicol 2008;252:40-8.

7. Paavilainen L, Edvinsson A, Asplund A, Hober S, Kampf C, Pontén F, et al. The impact of tissue fixatives on morphology and antibody-based protein profiling in tissues and cells. J Histochem Cytochem 2010;58:237-46.

8. Buesa RJ. Histology without formalin? Ann Diagn Pathol 2008;12:387-96.

9. Tadrous PJ. Digital stain separation for histological images. J Microsc 2010;240: 164-72.

10. Karapetis CS, Khambata-Ford S, Jonker DJ, O'Callaghan CJ, Tu D, Tebbutt NC, et al. K-ras mutations and benefit from Cetuximab in advanced colorectal cancer. N Engl J Med 2008;359:1757-65.

11. Boon ME, Kok LP. Theory and practice of combining coagulant fixation and microwave histoprocessing. Biotech Histochem 2008;83:261-77.

12. Fox CH, Johnson FB, Whiting J, Roller PP. Formaldehyde fixation. J Histochem
Cytochem 1985;33: 845-53.

13. O'Leary TJ, Fowler CB, Evers DL, Mason JT. Protein fixation and antigen retrieval: chemical studies. Biotech Histochem 2009;84:217-21.

14. Ramos-Vara JA. Technical aspects of immunohistochemistry. Vet Pathol 2005; 42:405-26.

15. Bussolati G, Leonardo E. Technical pitfalls potentially affecting diagnoses in immunohistochemistry. J Clin Pathol 2008;61:1184-92.

16. Srinivasan M, Sedmak D, Jewell S. Effect of fixatives and tissue processing on the content and integrity of nucleic acids. Am J Pathol 2002;161:1961-71.

17. Williams C, Pontén F, Moberg C, Söderkvist P, Uhlén M, Pontén J, et al. A high frequency of sequence alterations is due to formalin fixation of archival specimens. Am J Pathol 1999;155:1467-71.

18. Gillespie JW, Best CJM, Bichsel VE, Cole KA, Greenhut SF, Hewitt SM, et al. Evaluation of non-formalin tissue fixation for molecular profiling studies. Am J Pathol 2002;160:449-57.

19. Baloglu G, Haholu A, Kucukodaci Z, Yilmaz I, Yildirim S, Baloglu H. The effects of tissue fixation alternatives on DNA content: a study on normal colon tissue. Appl Immunohistochem Mol Morphol 2008; 16:485-92. 